\title{
Study on Casing Stability under Non-Uniform Ground Stress for In-Situ Leaching Well of One Uranium
}

\author{
Yang Lizhi, Li Po, Li Zhaokun, Hu Boshi \\ Beijing Research Institute of Chemical Engineering and Metallurgy, CNNC \\ 145 jiukeshu,Tongzhou District, Beijing, China \\ yanglizhi888@163.com; dijin@bricem.com.cn
}

\begin{abstract}
One in-situ leaching sandstone uranium deposit is located in the southern margin of Ili basin in northern Tianshan area. In order to study the effect of in-situ stress in deep ground on casing stability in long-term in-situ leaching operation process, we estimate the in-situ stress character in the mine based on the pie core and scan images of borehole TV, combining with the measured in-situ stress nearby. The results show that the direction of the maximum horizontal principal stress in the mine is $\mathrm{NNE}^{\circ} 6^{\circ}$, the magnitude of it is about 25.54 MPa.Within the scope of tested depth, the relationship among the magnitude of the principal stress is $\mathrm{SH}>\mathrm{SV}>\mathrm{Sh}$, the range of $\mathrm{SH} / \mathrm{SV}$ is 1.6-1.1, the range of $\mathrm{Sh} / \mathrm{SV}$ is 1.1-0.8, which indicate that the horizontal stress dominate control the stress field in this area. Taking UPVC casing- cement sheath-stratum combined system as study target, the finite models were established for rearch on the pressure and deformation effect of different factors and mud creep. The relation on the casing deformation and non-uniformity was studied. Furthermore, the casing life in creep formation was estimated. The numerical simulation results shows that the non-uniform ground stress is the important cause of main casing damage. Meanwhile the mudstone creep will aggravate the non-uniformity of the ground stress. The larger the stress differential is, the easier the casing will be plastic damage. Under the condition of non-uniform stress, the plastic strain reaches $14 \%$ at a depth of $720 \mathrm{~m}$ for 8 years and close to the plastic strain of $15 \%$. The casing is likely to be damaged or excessively deformed.
\end{abstract}

Keywords: Ground stress, Casing damage, Creep, Casing stability, Finite element analysis.

\section{Introduction}

Casing damage is a severe geological engineering problem often encountered in the development of oil fields domestically and abroad, which brings great harm to the normal production of oil fields. According to statistics, by the end of 1998, the number of case breaking in oil and gas fields in Daqing, Jilin, Dagang, North China, central China, Jianghan, Xinjiang, Yumen, Shengli, Sichuan and Liaohe oil and gas fields have reached more than 14000 wells. If the cost of each well is less than 1 million 500 thousand yuan, the direct economic losses have reached 21 billion yuan ${ }^{[1]}$. The change of ground stress is the main cause of the casing damage. Geostress is the natural stress in the earth's crust without engineering disturbance, also known as the initial stress, absolute stress or original rock stress in the rock mass, and in the broad sense it also refers to the stress within the earth.

In the in-situ-leaching well, the casing is also required to create a low resistance channel for the pumping and injection. The annular space between the outer wall of the casing and the hole wall is sealed with cement, and the casing and the cement ring separate the aquifers together, so that the injected solution and the extracted leaching solution are only existing in the designed of the layer ${ }^{[2]}$.

Usually, the leaching period lifetime of a ISL field is 5 10 years. When the crustal stress changes, the casing pipe will produce deformation or fault and form the casing damage, which seriously affects the normal production of the mine and causes huge economic loss. At present, the depth of in-situ leaching is less than $500 \mathrm{~m}$. The crustal stress has little effect on casing in the ISL well, but casing damage occurs occasionally.

With the continuous progress of geological exploration technology in China, the depth of prospecting is increasing, and a certain deposit in the Yili basin can reach $1023.3 \mathrm{~m}$. According to the theory of rock and soil mechanics, the outer pressure of the formation to the casing pipe wall can reach $60 \mathrm{Mpa}$, and the influence of ground stress on the mining of ISL could not been ignored any more. 
Based on the measurement results, based on the measurement results, the finite element method is used to establish the two-dimensional and three-dimensional finite element model of the UPVC casing cement ring formation composite structure, and the effect of the crustal stress field on the stability of the casing pipe is discussed in order to provide reference for the related engineering practice.

\section{Regional Geology}

A sandstone uranium deposit is located in the tectonic relative area of the eastern section of the southern margin of the Yili basin. It belongs to the southeast wing of the secondary tectonic unit, the East, West and south of the syncline, to the North East, to the open steamy syncline, and the oblique axis in the Yili River Valley (Figure 1).

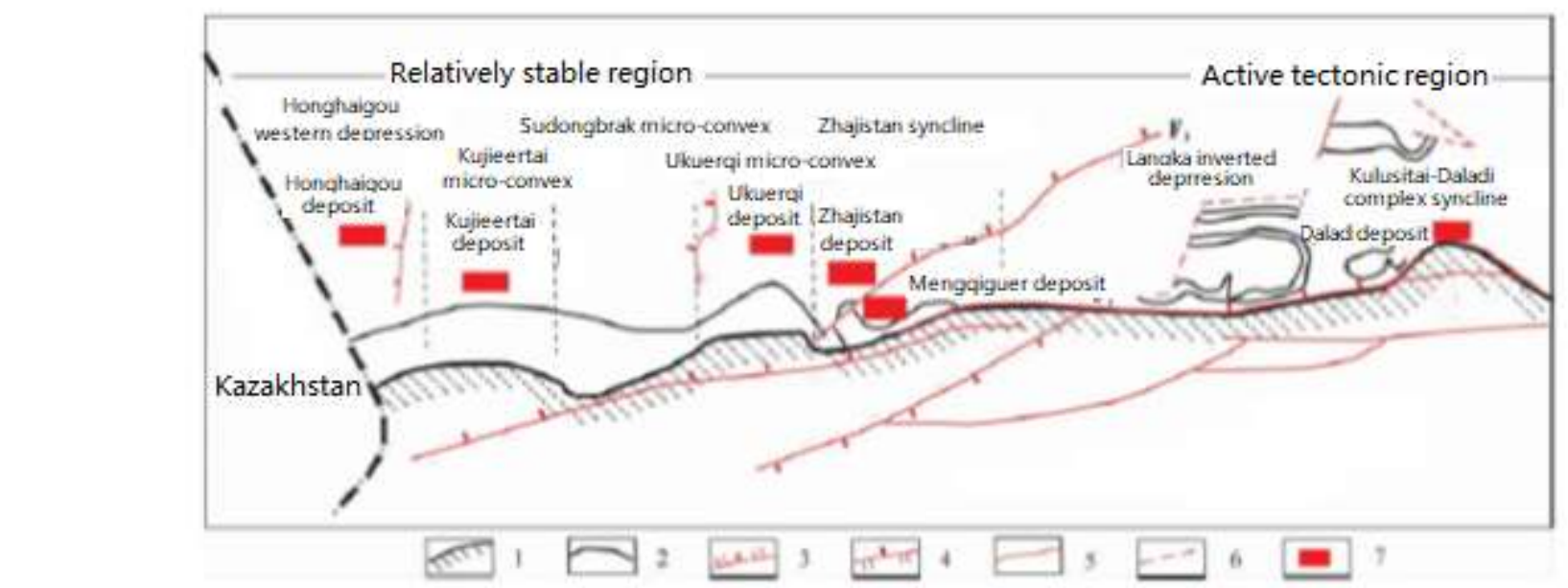

1-basin boundary; 2-outcrop of the tenth and eight coal seams; 3-normal fault; 4- reverse fault; 5-compression and torsion reverse fault; 6-unknown fault; 7-uranium deposit

Fig.1: regional tectonic map of the study area.

\subsection{State of stress in the study area}

\subsubsection{Direction of crustal stress}

The response of borehole wall to hole coring reflects the in-situ stress state and rock properties.Due to the uneven stress state in the rock mass of the earth's crust, the stress concentration in the borehole wall is formed after the formation of the borehole, and the stress concentration point in the direction of the minimum principal stress is the pressure stress concentration point, and the tension stress concentration point is formed in the direction of the maximum principal stress. When the compressive stress concentration exceeds the rock strength of the hole wall, the hole wall begins to destroy. When the secondary stress state around the wall reaches the balance again, the failure of the hole wall is stopped, which forms a new form of borehole. This phenomenon is called the borehole caving, the long axis of the borehole caving is the square of the minimum horizontal principal stress.A QL-ABI40 ultrasonic borehole television imaging comprehensive test systemisusedinthis study. Through the practical scanning of the SY-02 borehole in the study area, the complete borehole wall image is obtained. Through screening, the image of the borehole caving section which can reflect the information of the regional stress field and the geometric parameters of the borehole caving are obtained. As shown in Table 1, the direction of the maximum horizontal principal stress is $\mathrm{NNE}^{\circ} 6^{\circ}$. 
Table 1: Parameters of borehole caving images obtained by ultrasonic borehole televisions.

\begin{tabular}{|c|c|c|c|c|c|}
\hline $\begin{array}{l}\text { Depth of } \\
\text { borehole } \\
\text { caving } / \mathrm{m}\end{array}$ & $\mathrm{nd} /{ }^{\circ}$ & $\begin{array}{l}\text { Dip } \\
\text { angle }^{\circ}\end{array}$ & $\begin{array}{l}\text { Length/ } \\
\mathrm{m}\end{array}$ & \multicolumn{2}{|c|}{$\begin{array}{l}\text { Borehole caving angle } \\
\qquad \varphi \mathrm{b}) /^{\circ}\end{array}$} \\
\hline 707.50 & $.5^{183}$ & -4.9 & 0.5 & 65.68 & \multirow{2}{*}{64.20} \\
\hline 707.51 & $7^{21 .}$ & -2.2 & 0.5 & 62.72 & \\
\hline 707.91 & $.5^{203}$ & 2.2 & 0.3 & 42.47 & \multirow{2}{*}{39.51} \\
\hline 707.94 & $3^{15 .}$ & -5.7 & 0.3 & 36.54 & \\
\hline $\begin{array}{l}\text { Average } \\
\text { value }\end{array}$ & 16 & l & I & I & I \\
\hline
\end{tabular}

\subsubsection{Crustal stress practice value}

When drilling is carried out in a specific stress area, the core will appear as a regular short column, pancake or flake. In most cases, these cores are saddle shaped and sometimes the top and bottom of the core are parallel to each other. People generally call this phenomenon a cake core. Many research results show that this cake core is mainly caused by tensile stress generated during core drilling under specific stress field conditions. Generally, the cake core is shown in deep hole drilling process, so the stress information can be extracted from this phenomenon. The shape of the cake core can provide the maximum principal stress and the direction of the intermediate principal stress. The axis direction of the saddle shaped concave surface of the cake like core is the direction of the maximum principal stress, and the direction perpendicular to the axis direction is the direction of intermediate principal stress, as shown in figure $3^{[3-5]}$.

The cake core can also be used to analyze the magnitude of the in-situ stress field. In view of the stress estimation related to the cake core phenomenon, Obert and Stephenson carried out a large number of lab drilling simulation experiments. Through the analysis and summary of the experimental results, they got the stress condition empirical formula ${ }^{[6]}$ when the cake core occurred:

$$
\sigma_{r}=k_{1} \sigma_{b}+k_{2} \sigma_{z}
$$

In the formula, $\mathrm{K}_{1}$ is $6.5-10.5$ times the tensile strength of rock. It can be determined by the Brazil disk experiment; the range of $\mathrm{K}_{2}$ is $0.59-0.89$, depending on the rock condition. The analysis and cataloguing of some 40m cores obtained by SY02 drilling (Fig.2) and the ratio of the thickness (or axial length of the axial length) to the diameter (Table 2) were calculated, and the average value of the core was calculated to be 0.82 . 


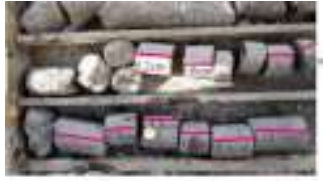

(a)

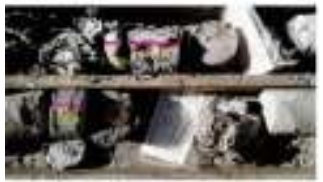

(d)

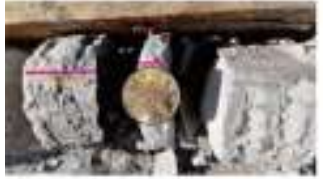

(g)

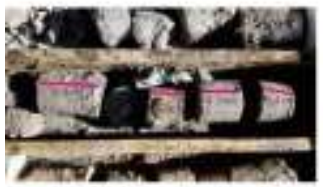

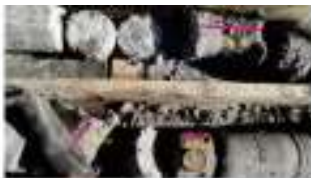

(b)

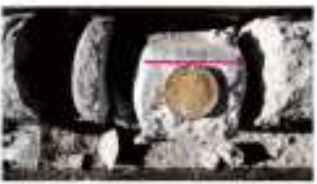

(e)

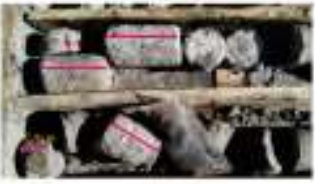

(II)

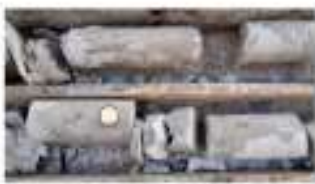

(k)

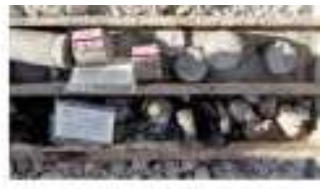

(e)

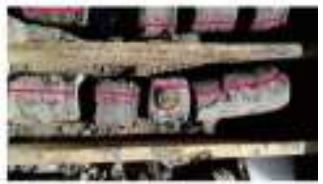

(f)

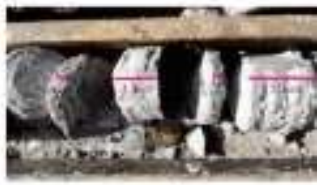

(i)

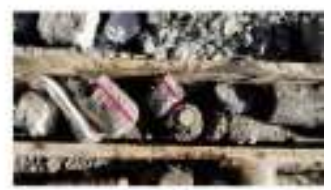

(1)

Fig. 2: The cataloguing and analysis of the cake core phenomenon of SY-02 drill.

Table 2: data analysis table for the phenomenon of drilled cake core.

\begin{tabular}{|c|c|c|c|c|c|c|c|}
\hline $\begin{array}{c}\mathrm{N} \\
\text { umber }\end{array}$ & $\begin{array}{l}\text { Firs } \\
\text { t Line }\end{array}$ & $\begin{array}{l}\text { Secon } \\
\text { d Line } \\
\end{array}$ & \begin{tabular}{c}
\multicolumn{1}{c}{$A$} \\
verage
\end{tabular} & $\begin{array}{c}\mathrm{N} \\
\text { umber }\end{array}$ & $\begin{array}{l}\text { First } \\
\text { Line }\end{array}$ & $\begin{array}{l}\text { Second } \\
\text { Line }\end{array}$ & $\begin{array}{c}\text { A } \\
\text { verage }\end{array}$ \\
\hline (a & $\begin{aligned} & 1.15 \\
, & 0.67 \\
0.73, & 0.29\end{aligned}$ & $\begin{aligned} & 1.49 \\
, & 0.961 .11 \\
, & 0.911 .24 \\
, \quad & 1.71\end{aligned}$ & $03^{1 .}$ & b) & $\begin{array}{l}1.24 \\
0.6\end{array}$ & $\begin{array}{l}0.76, \\
0.58\end{array}$ & $80^{0 .}$ \\
\hline (c & $\begin{array}{c}1.04 \\
, 0.87 \\
\end{array}$ & I & $96^{0 .}$ & d) & $\begin{array}{cc} & 0.24 \\
, & 1.0 \\
\end{array}$ & 0.64 & $63^{0 .}$ \\
\hline (e & $\begin{array}{l}0.2 \\
0.8\end{array}$ & I & $5^{0 .}$ & )$^{(f}$ & $\begin{array}{r}1.11 \\
, 0.760 .82 \\
, 0.73\end{array}$ & $\begin{array}{c}1.44, \\
0.910 .76 \\
1.98\end{array}$ & $06^{1 .}$ \\
\hline$)^{(g}$ & $\begin{array}{l}0.58 \\
, 0.2\end{array}$ & I & $39^{0 .}$ & h) & $\begin{array}{c}0.09 \\
, \quad 1.64 \\
1.47\end{array}$ & $\begin{array}{c}0.62, \\
1.27\end{array}$ & $02^{1 .}$ \\
\hline (i) & $\begin{array}{r}0.24 \\
, 0.78 \\
0.29, \quad 1.18 \\
\end{array}$ & I & $62^{0 .}$ & (j & $\begin{array}{r}1.42 \\
, 0.730 .96 \\
, 0.73 \\
\end{array}$ & I & $96^{0 .}$ \\
\hline$)^{(k}$ & I & I & I & )$^{(1}$ & $\begin{array}{l}1.51 \\
, 0.6\end{array}$ & I & $06^{1 .}$ \\
\hline \multicolumn{6}{|c|}{ Total average } & \multicolumn{2}{|c|}{0.82} \\
\hline
\end{tabular}


According to the data, the tensile strength of sandstone and mudstone and weak sandstone is $1.5 \mathrm{MPa}$, the density is 2.1 $\mathrm{g} / \mathrm{cm}^{3}, \mathrm{k}_{1}=12, \mathrm{k}_{2}=0.7$, the depth of the cake core is $730 \mathrm{~m}$, and the maximum principal stress value of the formula (1) is estimated to be $25.54 \mathrm{MPa}$.

\subsubsection{A discussion on the crustal stress field in the study area}

By consulting the measured geostress data in the North Tianshan Mountain Area (Fig.3) ${ }^{[6]}$, the maximum principal stress direction of the North Tianshan mountain area is N-S, the direction of the middle principal stress is W-E, and the minimum principal stress direction is NW-SE, which is similar to the result of the maximum principal stress direction in the study area.

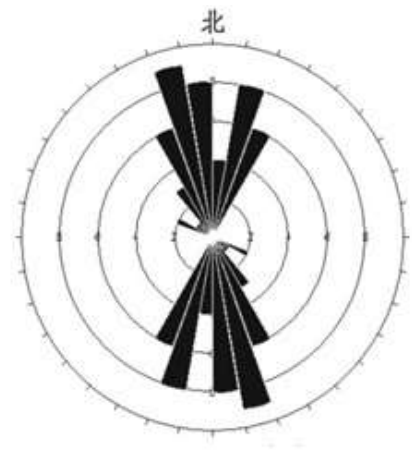

Maximum principal stress direction

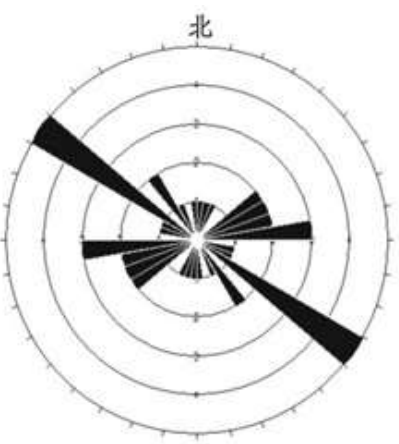

Minimum principal stress direction

Fig. 3: rose map of the principle stress direction in the North Tianshan Mountain Area.

In order to better estimate the stress level of the study area, the measured geostress data of the two projects in the Jing Yi Huo railway ${ }^{[7]}$ and the eighty-one Daban tunnel ${ }^{[8]}$ are screened out in the North Tianshan mountain area. According to the stress prediction method proposed by Wang Chenghu and so on, the maximum and minimum principle stress is normalized by the vertical principal stress. In order to eliminate the influence of test depth on the strength value, it is more convenient to reflect the stress state ${ }^{[9-10]}$ of different test depths. The lateral pressure coefficient $k_{\mathrm{H} \text { max }}\left(\mathrm{S}_{\mathrm{H}} / \mathrm{S}_{\mathrm{V}}\right)$ and $\mathrm{K}_{\mathrm{H} \text { min }}\left(\mathrm{S}_{\mathrm{h}} / \mathrm{S}_{\mathrm{V}}\right)$ were calculated respectively in two different test sections, and the relationship between the lateral pressure coefficient and the depth was obtained (Fig.4). According to the comparison of the fitting results, the calculated results of the borehole caving and the cake core, it is found that the relationship between the size of the three principal stresses is $S_{H}>S_{V}>S_{h}$, which indicates that the area is dominant in the shallow horizontal stress in the crust, and the current stress is more powerful; the range of $\mathrm{S}_{\mathrm{H}} / \mathrm{S}_{\mathrm{V}}$ is 1.6 1.1, and the range of $\mathrm{S}_{\mathrm{h}} / \mathrm{S}_{\mathrm{V}}$ is $1.1 \sim 0.8$.
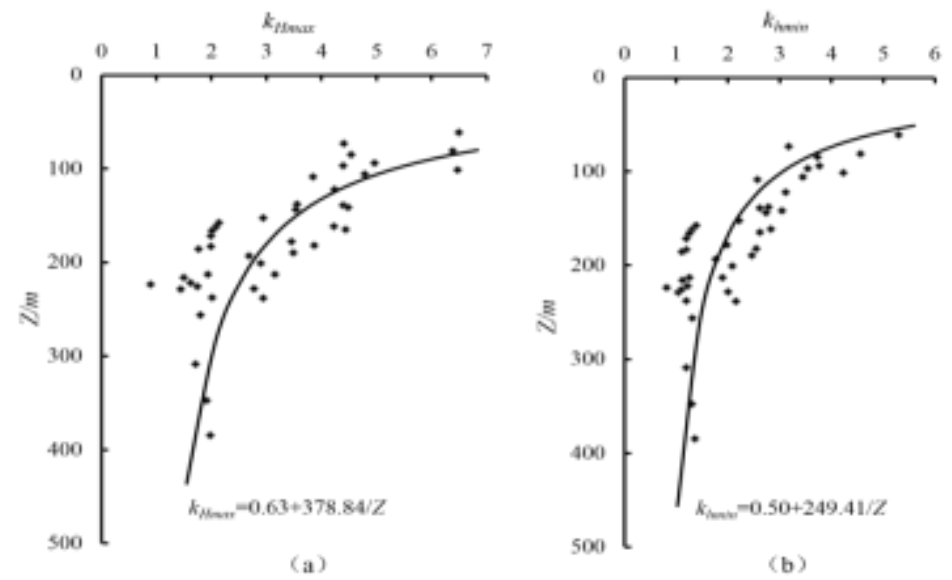

Fig. 4: the variation diagram of the lateral pressure coefficient with the depth of the study area. 


\section{Numerical simulation of casing deformation under non-uniform crustal stress}

According to the logging results of the SY-02 borehole in the mining area, mudstone interlayers are distributed at a depth of 721.35-722.05 m. During the development of water flooding in the in-situ mining, groundwater will enter the weak layer along the cracks in the rock formation, resulting in mudstone. And the strength properties of the weak sandstone change, thereby accelerating the creep rate of the rock formation, making the casing easy to be crushed and broken. Based on the results of the geostress measurement in the study area, the finite element method is used to establish the two-dimensional and three-dimensional finite element model of the UPVC casing cement ring formation composite structure, and the influence of the present geostress on the stability of the casing in the study area is discussed.

\subsection{The construction of the model}

Because the axial length of casing is much larger than that of other dimensions, it can be simplified as plane strain analysis. The stress distribution of UPVC casing cement ring stratum composite structure under non uniform stress field is shown in Fig.5, and the surrounding rock is composed of mudstone with creep. The two dimensional model has the advantages of saving calculation, but according to the results of borehole logging in mining area, the main stratum in the design depth is sandstone accompanied by mudstone and soft sandstone interlayer. The two dimensional model can exaggerate the creep effect of sandstone according to the creep stratum, and neglects the influence of the vertical stress. A two-dimensional and three-dimensional finite element model is established respectively. The two dimensional model focuses on the influence of different factors on the force and deformation of the casing. The three-dimensional model focuses on the problem of stress and deformation caused by the creep of the rock under the action of the actual stratum and the present stress field.

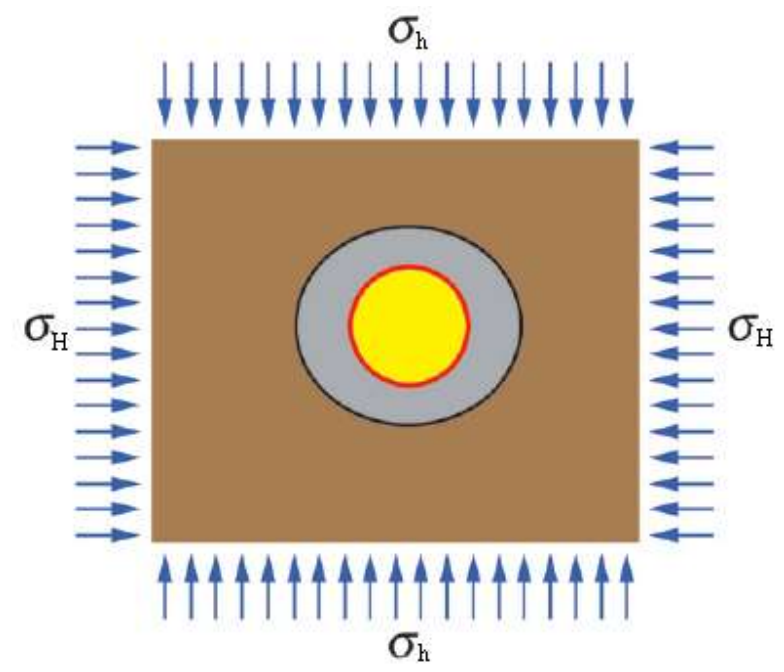

Fig. 5: PVC-U casing cement ring formation system.

The following assumptions are made when the model is established:

(1) the surrounding rock of cement ring and shaft wall is homogeneous isotropic body.

(2) UPVC casing has no defects, cement ring is intact and thickness is uniform.

(3) the contact surfaces of the composite body are tightly connected without sliding. 


\subsection{Model grid division}

Due to the symmetry of the geometry and boundary conditions, only a quarter of the computational model can be considered for calculation. Since the first-order triangular element is a constant-strain element and the integral precision is low, the two-dimensional model meshing uses a second-order triangular mesh. When meshing, the mesh is dense near the circular hole, and the farther and farther is sparse, The total number of 2D model units is 5074, and the total number of nodes is 1618 (Fig.6). The 3D model mesh is divided into a first-order triangular prism grid with a total number of units of 101480 and a total number of nodes of 54978 (Fig.7). The size of the three-dimensional model is $0.52 \mathrm{~m} \times 0.52 \mathrm{~m} \times 1 \mathrm{~m}$, the depth of the top surface is $721.2 \mathrm{~m}$, and the depth of the bottom surface is $722.2 \mathrm{~m}$, of which the thickness of mudstone and soft sandstone is $0.7 \mathrm{~m}$. The hole diameter is $269 \mathrm{~mm}$, the cement ring is (inner diameter $\times$ wall thickness) $\Phi 128 \mathrm{~mm} \times 70.5 \mathrm{~mm}$, and the PVC pipe is (inner diameter $\times$ wall thickness) $\Phi 104 \mathrm{~mm} \times 12 \mathrm{~mm}$.

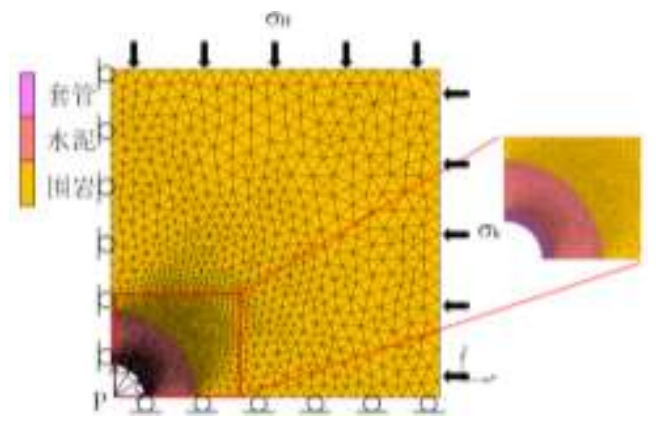

Fig. 6: Schematic diagram of 2D finite element model meshing.

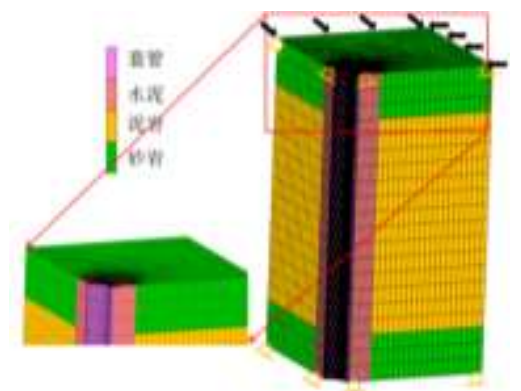

Fig. 7: Schematic diagram of 3D finite element model meshing.

\subsection{Boundary condition setting}

A radial internal pressure is applied to the inner diameter of the casing, and the internal pressure $\mathrm{P}$ is superposed by the injection pressure and the hydrostatic pressure of the injection liquid itself, and the injection pressure is $1 \mathrm{MPa}$ as designed. Due to the symmetry, the symmetry plane (left and lower boundaries) imposes a normal displacement constraint, and the upper and right boundaries respectively apply horizontal minimum and maximum principal stresses (Fig. 7).

\subsection{Boundary condition setting}

The model assumes that the rheological model of mudstone and weak sandstone formation is Maxwell body, and the damage of casing is the main analysis object. The casing material adopts the ideal elastoplastic material obeying the Von Mises yield criterion, and the cement adopts the Drucker-Prager quasi-yield criterion. The ideal elastoplastic material. According to the research results of Pantelelis and Kanarachos, the PVC pipe used by us has a plastic strain of $15 \%$. Since the cement still has partial bearing capacity after cracking, we use the "killing unit" method to simulate partial loss of bearing capacity after cement cracking, and the cement has low tensile strength. In our simulation, cracking occurs when the tensile 
stress reaches $6 \mathrm{MPa}$. The elastoplastic parameters of the material in the casing-cement ring-stratigraphic system are listed in Table 3. In order to investigate the casing stability under long-term operation of the in-situ test site, the calculation time was set to 20 years. In our calculations, a risk factor $\mathrm{C}$ is defined as an indicator of casing stability:

$$
\mathrm{C}=\left(\varepsilon^{\mathrm{P}} / \varepsilon^{\mathrm{P}} \mathrm{C}\right)-1
$$

Among them, $\varepsilon^{\mathrm{P}}$ is the calculated equivalent plastic strain, $\varepsilon^{\mathrm{P}} \mathrm{c}$ is the critical failure plastic strain, this time $\varepsilon^{\mathrm{P}} \mathrm{c}=15 \%$, when the risk factor is greater than 0 , the casing may have plastic damage.

Table 3: The material parameters of borehole pressure numerical simulation.

\begin{tabular}{|c|c|c|c|c|c|c|c|}
\hline Materical & $\begin{array}{c}\text { Density } \\
/ \mathrm{cm}^{3}\end{array}$ & $\begin{array}{c}\text { Elastic Modulus } \\
\mathrm{GPa}\end{array}$ & $\begin{array}{c}\text { Poisson's } \\
\text { ratio }\end{array}$ & $\begin{array}{c}\text { Cohesion } \\
\mathrm{MPa}\end{array}$ & $\begin{array}{c}\text { Internal } \\
\text { friction } \\
\text { angle }\end{array}$ & $\begin{array}{c}\text { Yield stress } \\
\text { plasticity } \\
\mathrm{MPa}\end{array}$ & $\begin{array}{c}\text { Destructive } \\
\text { strain }\end{array}$ \\
\hline Sandstone & 2.09 & 20 & 0.25 & 10 & 40 & - & - \\
\hline Mudstone & 2.09 & 20 & 0.35 & 10 & 23 & - & - \\
\hline Cement & 1.7 & 7.0 & 0.17 & 15 & 30 & - & \\
\hline $\begin{array}{c}\text { UPVC } \\
\text { pipe }\end{array}$ & 1.4 & 3.4 & 0.3 & - & - & 27.5 & $15 \%$ \\
\hline
\end{tabular}

\section{Numerical simulation results and analysis}

\subsection{Results and analysis of two-dimensional finite element model}

We studied the effect of ground stress levels on casing stability by changing the $S_{\mathrm{h}} / \mathrm{S}_{\mathrm{V}}$ and horizontal principal stress ratio $\mathrm{SH} / \mathrm{Sh}$. From the foregoing, it is known that $\mathrm{S}_{\mathrm{h}} / \mathrm{S}_{\mathrm{V}}=0.8-1.1$ and $\mathrm{S}_{\mathrm{H}} / \mathrm{S}_{\mathrm{h}}=1-2$. Taking a calculated depth of $700 \mathrm{~m}$, the casing is assumed to be an ideal plastic material (Von Mises stress does not exceed 27.5MPa), first fixed $S_{\mathrm{h}}=0.8 \mathrm{~S}_{\mathrm{V}}$, and the horizontal principal stress ratio is changed by changing the $S_{H}$ size, and 6 sets of different horizontal principal stresses are calculated. Casing stability under specific conditions; $S_{H}=2 S_{h}$ was fixed, $S_{h} / S_{V}$ was changed by changing $S_{h}$ size, and casing stability under four different $S_{h} / S_{V}$ conditions was calculated (Table 4$)$.

Table 4: Effect of different $S_{H} / S_{h}$ ratio on casing stability in creep formation.

\begin{tabular}{|r|c|c|c|c|}
\hline \multicolumn{1}{|c|}{$\mathrm{S}_{\mathrm{H}} / \mathrm{S}_{\mathrm{h}}$} & Maximum plastic strain & Risk factor C & $\begin{array}{c}\text { Maximum Von Mises stress } \\
\text { MPa }\end{array}$ & $\begin{array}{c}\text { Maximum radial displacement in 20 } \\
\text { yearsmm }\end{array}$ \\
\hline 1.0 & 0 & -1.00 & 27.2 & 0.6 \\
\hline 1.2 & $0.3 \%$ & -0.98 & 27.5 & 1 \\
\hline 1.4 & $0.8 \%$ & -0.95 & 27.5 & 1 \\
\hline 1.6 & $2.3 \%$ & -0.85 & 27.5 & 2.2 \\
\hline 1.8 & $11.2 \%$ & -0.25 & 27.5 & 4.5 \\
\hline 2.0 & $26.4 \%$ & 0.76 & 27.5 & 14.8 \\
\hline 3.0 & $77.6 \%$ & 4.17 & 27.5 & \\
\hline
\end{tabular}

It can be seen from Fig.8(a), (b), (c) that the part with the largest risk factor of the casing corresponds to the part where the Von Mises stress of the casing reaches the yield strength, and the connection between the most dangerous part of the casing and the center of the casing is approximated. Parallel to the horizontal minimum principal stress, the casing becomes elliptical under ground stress, and the long axis of the ellipse is perpendicular to the horizontal maximum principal stress. At $\mathrm{S}_{\mathrm{h}}=0.8 \mathrm{~S}_{\mathrm{V}}$, when $\mathrm{S}_{\mathrm{H}} / \mathrm{S}_{\mathrm{h}}=1.0$ is the uniform stress field, the casing does not enter yield; when $\mathrm{S}_{\mathrm{H}} / \mathrm{S}_{\mathrm{h}}>1.2$ casing begins to enter plastic; when $\mathrm{S}_{\mathrm{H}} / \mathrm{S}_{\mathrm{h}}>1.6$, maximum plastic strain and maximum radial When the displacement suddenly increases, the risk of damage to the casing increases greatly; the maximum plastic strain of the $S_{H} / S_{h}=2.0$ casing is much greater than the failure 
of the plastic strain, and the casing is destroyed. It can be seen from Fig.8(a) and (b) that the maximum deformation deformation zone of the casing and the maximum radial displacement of 20 years are continuously increased with the increase of $S_{\mathrm{H}} / S_{\mathrm{h}}$ under the other factors. The tube is prone to damage; it can be seen from Fig. 6(c) and (d) that at $S_{\mathrm{H}}=2 \mathrm{~S}_{\mathrm{h}}$, as the $\mathrm{S}_{\mathrm{h}} / \mathrm{S}_{\mathrm{V}}$ increases, the differential stress $\mathrm{S}_{\mathrm{H}-} \mathrm{S}_{\mathrm{h}}$ increases, and the maximum deformation deformation zone of the sleeve and The maximum radial displacement in 20 years is also increasing, and the risk of damage to the casing is increased.
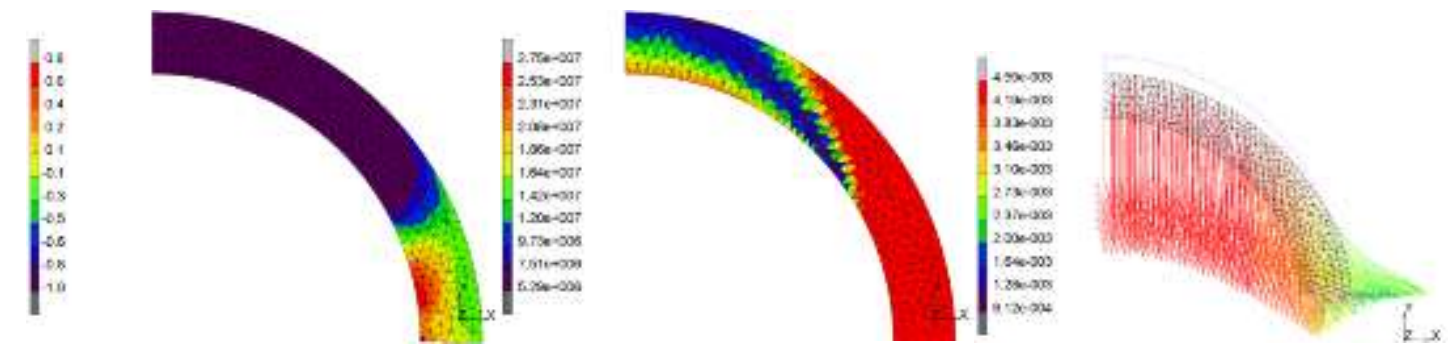

(a) risk factor C cloud map (b) Von Mises stress cloud map (c) displacement vector

Fig. 8: The result of numerical simulation.

\section{Conclusion}

(1) Through the calculation of drilling television images and pie cores, the maximum horizontal principal stress in the mining area is NNE16 degrees and the value is $25.54 \mathrm{MPa}$. According to the measured geostress data in the North Tianshan mountain area, the relationship between the three principal stresses in the area of the mining area is shown as: $S_{H}>S_{V}>S_{h}$, which indicates that the horizontal stress in the shallow crust is dominant in the area, and the present stress is more intense. Through the statistical analysis of the in-situ stress data, it is known that in the range of $400 \mathrm{~m} \sim 800 \mathrm{~m}$, the range of $\mathrm{S}_{\mathrm{H}} / \mathrm{S}_{\mathrm{V}}$ is 1.6 1.1 and the range of $\mathrm{S}_{\mathrm{h}} / \mathrm{S}_{\mathrm{V}}$ is $1.1 \sim 0.8$.

(2) By the analysis of numerical simulation results, it is found that the inhomogeneous ground stress is an important cause of casing damage. The creep of the corresponding mudstone will aggravate the inhomogeneity of the stress and accelerate the damage of the casing. The stress ratio $S_{H} / S_{h}$ and $S_{h} / S_{V}$ directly affect the stability of the casing. Different $S_{H} / S_{h}$ and $\mathrm{S}_{\mathrm{h}} / \mathrm{S}_{\mathrm{V}}$ ratios lead to the difference of stress, and the greater the differential stress, the more easily plastic failure occurs in the casing.

\section{References}

[1] Diao Shun, "Mechanism of seepage induced casing damage and numerical simulation," Rock and Soil Mechanics, vol. 29, no. 2, pp. 327-332, 2008.

[2] Wu Aixiang, "Progress and prospects of leaching mining technology," Mining Technology, vol. 6, no. 3, pp. 39-48, 2006.

[3] Wang Chenghu, "Brief Review and Outlook of Main Estimate and Measurement," Geological Review, vol. 60, no. 5, pp. 971-996, 2004.

[4] M. D. Zoback, Reservoir Geomechanics. New York: Cambridge University Press, 2007.

[5] A. Zang, O. Stephansson. Stress Field of the Earth's Crust. London:Springer, 2010.

[6] Zhang Jie. "The analysis about characteristics of in-situ stress fiels in xinjiang tianshan area," Journal of Engineering Geology, vol. 24, pp. 1370-1377, 2016.

[7] J. C. Jaeger and N. G. W. Cook, Fundamentals of Rock Mechanics. 3rd Ed, London:Chapman and Hall,1-593. 1979.

[8] B. C. Haimson, "Borehole breakouts core disking as tools for estimating in situ stress in deep holes," in Rock Stress, Sugawara K, Obara Y. Eds. Rotterdam: Balkema, pp. 35-42, 1997.

[9] L. Obert, D. E. Stephenson, "Stress conditions under which core discing occurs," Trans. SME, vol. 232, pp. $227-235$. 1965. 
[10] K. Matsuki, N. Kagaa, T. Yokoyama, N. Tsuda N, "Determination of three dimensional in situ stress from core discing based on analysis of principal tensile stress," International Journal of Rock Mechanics and Mining Sciences, vol. 41, no. 6 , pp. 1167-1190, 2004. 